Journal of Social Sciences 4 (1): 7-9, 2008

ISSN 1549-3652

(C) 2008 Science Publications

\title{
The Volatility and Asymmetry of Won/Dollar Exchange Rate
}

\author{
${ }^{1}$ Seok Yoon and ${ }^{2} \mathrm{Ki}$ Seong Lee \\ ${ }^{1}$ Korea National Assembly Library, 1 Yoido-dong, Youngdeungpo-ku, \\ Seoul, 150-703, Korea \\ ${ }^{2}$ Department of Economics, KonKuk University, 1 Hwayang-dong, \\ Kwangjin-ku, Seoul, 143-701, Korea
}

\begin{abstract}
The study on volatility and asymmetry of the exchange rate by applied to the daily Won/Dollar exchange rate shows that past volatility of the exchange rate still has strong persistency at present and asymmetry effect and the leverage effect, which explain that volatility shock has an effect on the uncertainty of the exchange rate, are also existent after the free floating exchange rate system was adopted.
\end{abstract}

Key words: Won/Dollar exchange rate, volatility, asymmetry, GARCH, TARCH, EGARCH

\section{INTRODUCTION}

The uncertainty of the exchange rate in Korea, which has a small open economy that shows a tendency to be dependent on foreign countries, has been sharply increased due to the increase in the volatility of the exchange rate by the regime shifts such as execution of the free floating exchange rate system and foreign exchange and capital account liberalization since the currency crisis of December, 1997.

Generally, the uncertainty of the exchange rate shows us how much economic behaviors are not able to perceive the directionality of the actual or future volatility of exchange rate, that is, it is a different concept from the volatility of the exchange rate itself in that it means that the more forecast errors of economic behaviors made, the higher the trends in the uncertainty of the exchange rate are shown.

The uncertainty of the exchange rate has a tendency to be inconstant, rather than to be fixed in the time-varying cases, that is to say, it has a feature of not homoskedasticity but conditional heteroskedasticity, which means that past information, is able to have an impact on future movements.

One of the examples of conditional heteroskedasticity is the generalized ARCH (GARCH) model of Bollerslev ${ }^{[1]}$. The GARCH model is said to be a fit model, which is able to explain and describe the volatility clustering phenomenon. In this model, however, asymmetric volatility, which shows more critical reactions to negative shocks than to the same amount of positive ones, is also founded.
Therefore, a certain problem will appear when we assume circumstances on the basis of the GARCH model, which presumes a symmetric reaction to shocks, in that we might underestimate negative shocks and overestimate positive shocks. Due to this kind of problem in assumption, we can also use the TARCH (threshold ARCH) model of Glosten, Jagannathan and Runkle ${ }^{[2]}$ and the exponential GARCH (EGARCH) model of Nelson ${ }^{[3]}$ which specialized in measuring asymmetric volatility of the exchange rate.

This study adopts GARCH $(1,1)$, TARCH $(1,1)$ and EGARCH $(1,1)$ models in order to estimate the volatility and asymmetry of the daily Won/Dollar exchange rate.

\section{GARCH, TARCH AND EGARCH MODELS}

The need of long lag to improve the goodness of fit when we adopt the autoregressive conditional heteroskedasticity (ARCH) model occurs at times. To overcome this problem, Bollerslev (1986) suggested the generalized ARCH (GARCH) model, which means that it is a generalized version of ARCH. The GARCH model considers conditional variance to be a linear combination between squired of residual and a part of lag of conditional variance.

This simple and useful GARCH is the dominant model applied to financial time series analysis by the parsimony principle. GARCH $(1,1)$ model can be summarized as follows:

$$
\varepsilon_{\mathrm{t}} \mid \mathrm{I}_{\mathrm{t}-1} \sim \mathrm{N}\left(0, \sigma_{\mathrm{t}}^{2}\right)
$$

Corresponding Author: Seok Yoon, Korea National Assembly Library, 1 Yoido-dong, Youngdeungpo-ku, Seoul, 150-703, Korea, Tel: +82-2-788-4353 


$$
\sigma_{t}^{2}=\omega+\alpha \varepsilon_{t-1}^{2}+\beta \sigma_{t-1}^{2}
$$

In this formula, $\sigma_{\mathrm{t}}^{2}$ is conditional variance of $\varepsilon_{\mathrm{t}}$ and $\omega>0, \alpha \geq 0, \beta \geq 0$. In formula 2 , the equation will be stationary if the sum of the ARCH coefficient $\alpha$ and the GARCH coefficient $\beta$ is less than 1 and in the case it comes much closer to 1 , volatility shocks will be much more stationary.

The GARCH model has a distinctive advantage in that it can track the fat tail of asset returns or the volatility clustering phenomenon very efficiently, but it also has a weak point in that the conditional variance in GARCH model is merely dependent on the magnitude of the previous error term and is not related to its sign. In other words, it can not reflect leverage effects, a kind of asymmetric information effects that have more crucial impact on volatility when negative shocks happen than positive shocks do. To solve this problem, asymmetric effect caused by error term should also be reflected in the GARCH model.

Glosten, Jagannathan and Runkle (1993) suggested the TARCH (threshold ARCH) model (or GJR model), considering those facts. The conditional variance of TARCH $(1,1)$ can be summed up as follows:

$$
\sigma_{t}^{2}=\omega+\alpha \varepsilon_{t-1}^{2}+\gamma \varepsilon_{t-1}^{2} d_{t-1}+\beta \sigma_{t-1}^{2}
$$

where $\mathrm{d}_{\mathrm{t}}=1$ if $\varepsilon_{\mathrm{t}}<0$ and $\mathrm{d}_{\mathrm{t}}=1$ otherwise. In formula 3 , if $\gamma \neq 0$, it means it is asymmetric and if $\gamma>0$, we can say there is a leverage effect. If the effect is existent and $\alpha+\beta+(\gamma / 2)$ is less than 1 , the conditional variance is stationary.

The TARCH model can explain asymmetry of the conditional variance about shocks with a very simple equation, but it should restrict parameters to make variance positive.

Nelson (1991) suggested the EGARCH (exponential GARCH) model, which could make the conditional variance positive regardless of the plus or minus sign of parameter in the EGARCH (exponential GARCH) model by applying logarithm to $\sigma_{t}^{2}$ in the conditional variance equation. Unlike the GARCH model, it doesn't have to restrict the parameter to obtain stationary estimation, which makes the process of numerical optimization a simpler and dynamic model for conditional variance available. Furthermore, in the EGARCH model, conditional variance is dependent on sign as well as magnitude like the TARCH model.

The conditional variance of EGARCH $(1,1)$ model can be summed up as follows:

$$
\log \sigma_{t}^{2}=\omega+\beta \log \sigma_{t-1}^{2}+\alpha\left|\frac{\varepsilon_{t-1}}{\sigma_{t-1}}-\sqrt{\frac{2}{\pi}}\right|+\gamma \frac{\varepsilon_{t-1}}{\sigma_{t-1}}
$$

In formula 4, applying logarithm seems to be distinctive, which means that the leverage effect is formed not as quadratic equation but as an exponential function, that is, forecasts of conditional variance can not be negative.

In the above conditional variance formula, if $|\beta|$ is less than 1 , the formula is stationary. Also, $\varepsilon_{t-1} / \sigma_{t-1}$ terms are standardized residuals of a previous period and those terms can let us know whether the asymmetry effect is existent or not by the magnitude and sign of parameter $\gamma$. In other words, we presume the existence of the asymmetry effect if the result of testing null hypothesis, $H_{0}: \gamma=0$ comes to $\gamma \neq 0$, especially in case of $\gamma<0$, the leverage effect is considered to be existent as well.

\section{DATA AND ESTIMATION RESULTS}

The time series data used in this analysis was the Won/Dollar exchange rate (close), which was daily data from March 2, 1998 to June 30, 2006. The number of observed values derived from these data was 2,153 . First of all, to make sure the stationarity of time series data, logarithm was applied to level variable and then the Augmented Dickey-Fuller(ADF) test ${ }^{[4]}$ and the Phillips-Perron test ${ }^{[5]}$ were conducted. The test results are shown in Table 1.

As you see in Table 1, the level variable can make a null hypothesis, which assumed the unit root was existent, but rejected, but the first order difference variable appeared to be a stationary time series because the null hypothesis was rejected under the $1 \%$ significance level. In this study, returns are defined as first order log difference as follows:

$$
r_{t}=\log \left(\frac{e_{t}}{e_{t-1}}\right) \times 100
$$

Where e mean the Won/Dollar exchange rate. Also, the GARCH $(1,1)$, TARCH $(1,1)$ and EGARCH $(1,1)$ models are used to estimate the asymmetry effect and the leverage effect, which show that Won/Dollar exchange rate and volatility shocks can highly impact on the uncertainty of exchange rate and the result of assumption are as follows. 
Table 1: Unit root test for daily Won/Dollar exchange rate from March 1998 to June 2006

\begin{tabular}{|c|c|c|c|c|}
\hline & \multicolumn{2}{|l|}{ ADF test } & \multicolumn{2}{|c|}{ Phillips-Perron test } \\
\hline & Level & First difference & Level & First difference \\
\hline Won/Dollar exchange rate & -2.245526 & $-42.52426^{*}$ & -2.398571 & $-42.62155^{*}$ \\
\hline \multicolumn{5}{|c|}{$\begin{array}{l}\text { Notes: } 1 \text { - *indicates that null hypothesis, which assumed the unit root was existent under the } 1 \% \text { significance level, but was rejected } \\
2 \text { - the level variable included constant and trend, but the difference variable only included constant, when the test were carried out }\end{array}$} \\
\hline \multicolumn{5}{|c|}{$\begin{array}{l}\text { Table 2: Estimation results of the GARCH }(1,1) \text {, TARCH }(1,1) \text { and EGARCH }(1,1) \text { for daily Won/Dollar exchange rate from March } 1998 \text { to June } \\
2006\end{array}$} \\
\hline Parameters & GARCH $(1,1)$ & \multicolumn{2}{|c|}{ TARCH $(1,1)$} & EGARCH $(1,1)$ \\
\hline \multirow[t]{2}{*}{$\omega$} & $0.003258 * * *$ & \multicolumn{2}{|c|}{$0.003077 * * *$} & $-0.195062 * * *$ \\
\hline & $(6.751810)$ & \multicolumn{2}{|c|}{$(6.722199)$} & $(-16.70306)$ \\
\hline \multirow[t]{2}{*}{$\alpha$} & $0.089413 * * *$ & \multicolumn{2}{|c|}{$0.077816^{* * *}$} & $0.211149 * * *$ \\
\hline & (12.65754) & \multicolumn{2}{|c|}{ (9.753497) } & (16.99489) \\
\hline \multirow[t]{2}{*}{$\beta$} & $0.899246^{* * *}$ & \multicolumn{2}{|c|}{$0.901968^{* * *}$} & $0.974796 * * *$ \\
\hline & (141.9825) & \multicolumn{2}{|c|}{$(148.1659)$} & $(327.5611)$ \\
\hline \multirow[t]{2}{*}{$\gamma$} & - & \multicolumn{2}{|c|}{$0.019505^{*}$} & $-0.016325 * *$ \\
\hline & - & \multicolumn{2}{|c|}{ (1.916844) } & $(-2.278050)$ \\
\hline Log likelihood & -1281.242 & \multicolumn{2}{|c|}{-1280.186} & -1290.351 \\
\hline
\end{tabular}

Note: Each $* * *, * * *$ : mean they are significant under 10,5 and $1 \%$ significance levels and the parentheses are $\mathrm{z}$-statistic numbers

In the result of assumption using the GARCH $(1,1)$, TARCH $(1,1)$ and EGARCH $(1,1)$ models, all parameters were statistically significant and these models appeared to be suitable for assumption in that their conditional variance equations were all stationary on the ground that $\alpha+\beta$ was 0.989 in $\operatorname{GARCH}(1,1)$, $\alpha+\beta+(\gamma / 2)$ was 0.990 in TARCH $(1,1)$ and $\beta$ was 0.975 in EGARCH $(1,1)$, that is, they all were close to 1 .

Therefore, as the result of the assumption in TARCH $(1,1)$ and EGARCH $(1,1)$ models, the asymmetry effect and the leverage effect, which have a huge influence on Won/Dollar exchange rate, were existent, showing one $\gamma$ was positive and the null hypothesis was rejected and the other $\gamma$ was negative. These results mean that uncertainty has grown higher in case of unexpected negative shocks such as depreciation than the same size as positive shocks, accompanied with an increase in volatility of the exchange rate after the free floating exchange rate system was adopted.

\section{CONCLUSION}

As a result of analyzing volatility and asymmetry of the exchange rate after the free floating exchange rate system was adopted, these models appeared to be suitable in that all parameters of the models were statistically significant and their conditional variance equations were all stationary. Moreover, the asymmetry effect and the leverage effect, which led to the Won/Dollar exchange rate, were existent on the assumption by TARCH $(1,1)$ and EGARCH $(1,1)$ models. Therefore, uncertainty of the exchange rate has been increasing and volatility of the exchange rate, which can cause the uncertainty of domestic and foreign financial markets, has been persistent because of the regime shifts such as execution of the free floating exchange rate system and exchange and capital account liberalization.

\section{ACKNOWLEDGEMENT}

The author is grateful for excellent study assistance by the Librarian of the National Assembly. This work was supported by the Konkuk University Research Fund.

\section{REFERENCES}

1. Bollerslev, T., 1986. Generalized autoregressive conditional heteroskedasticit. J. Econometrics, 31: 307-327.

2. Glosten, L.R., R. Jagannathan and D.E. Runkle, 1993. On the relation between the expected value and the volatility of the normal excess return on stocks. J. Finance, 48: 1779-1801.

3. Nelson, D.B., 1991. Conditional heteroskedasticity in asset returns: a new approach. Econometrica, 59: 347-370.

4. Dickey, D.A. and W.A. Fuller, 1979. Distribution of the estimators for autoregressive time series with a unit root. J. Am. Stat. Assoc., 74: 427-431.

5. Phillips, P.C.B. Phillips and P. Perron, 1988. Testing for a unit root in time series regression. Biometrica, 75: 335-346. 